\title{
The Application of the Spirit of Beidahuang on Teaching Agricultural and Forestry Talents with Mass Entrepreneurship and Innovation: A Case Study of Heilongjiang Bayi Agricultural University in China
}

Yingce Zhan, Yuxian Zhang, Yanyan Chen, Jun Li, Yuan Yuan, Mingcong Zhang*

Heilongjiang Bayi Agricultural University, Daqing 163319, China

DOI: 1 10.36348/jaep.2020.v04i02.003 $\quad$ | Received: 09.02.2020 | Accepted: 17.02 .2020 | Published: 19.02 .2020

*Corresponding author: Mingcong Zhang

Abstract

The 19th National Congress of the Communist Party of China emphasizes the construction of an innovative country, and the country cannot be separated from the support of innovative talents. Colleges and universities undertake the important task of talent training, which puts forward new requirements to cultivate mass entrepreneurship and innovation talents to meet the needs of social development. The spirit of Beidahuang is that the masses of the people in Heilongjiang Reclamation area have cultivated and refined the spirit of " painstaking efforts of pioneering spirit, the innovative spirit of daring to open, the unity spirit of pay attention to the interest of the whole, the service spirit of selfless dedication" under the specific historical conditions and extremely difficult environment. Based on analyzing the internal relation between the spirit of Beidahuang and the cultivation of the agricultural and forestry talents with mass entrepreneurship and innovation, this paper explores excavating the spiritual and material resources of the Beidahuang through the three modes of practical teaching. Youths in New Age may strengthen the professional base, devote themselves consciously to the construction of modernization agriculture, put their own actions into the social practice of realizing the great rejuvenation of the Chinese nation.

Keywords: The Spirit of Beidahuang; Mass entrepreneurship and Innovation; Higher Education; Agricultural Institutions; Innovation Talent Training.

Copyright @ 2020: This is an open-access article distributed under the terms of the Creative Commons Attribution license which permits unrestricted use, distribution, and reproduction in any medium for non-commercial use (NonCommercial, or CC-BY-NC) provided the original author and sources are credited.

\section{INTRODUCTION}

Comrade Xi Jinping, Chairman of the Chinese Communist Party made clear in the report of the Nineteenth National Congress of the Communist Party of China that the masses of the people should extensively carry out education on ideals and beliefs, deepen the propaganda and education of socialism with Chinese characteristics and Chinese Dream, promoting the national spirit and the spirit of the times, strengthen the education of patriotism, collectivism and socialism, and guide people to establish a correct view of history, nationality, state and culture [1]. Throughout the history of China's development, in the period of the new democratic revolution, the spirit of Jinggangshan, the spirit of the Long March, the spirit of Yan'an and the spirit of the Red Boat fully embodied the great national spirit of peace-loving and self-improvement with patriotism as the core. The spirit of Daqing and the spirit of Beidahuang formed in the course of the construction of the new China have been handed down to the spirit of the solidarity and unity, hard-working and brave of the Chinese nation after the founding of the People's Republic of China. Since the reform and openness in China, the spirit of flood prevention and rescue, the spirit of fighting against SARS, the spirit of manned space flight and the spirit of the Qinghai-Tibet Railway are the concentrated embodiment of the tenacious national spirit in the new period of China.

In the 1950s and 1960s, the spirit of Beidahuang was formed during the development and construction of 100,000 troops, 120,000 border youths, 540,000 intellectual youths and other builders of reclamation areas. The spirit of Beidahuang including many elements of youth growth, such as theory, quality, morality, will, personality charm were a good idea and a good style of work formed [2]. In the early 1990s, the Party Central Committee concentrated on the understanding and wisdom of the Beidahuang people, the basic connotation with the spirit of the Beidahuang is summarized as follows: painstaking efforts of pioneering spirit, the innovative spirit of daring to open, 
the unity spirit of pay attention to the interest of the whole, the service spirit of selfless dedication.

The inherent relationship between the spirit of Beidahuang and the cultivation of training agricultural and forestry talents with mass entrepreneurship and innovation

The development of talent needs the guidance of the Beidahuang spirit

Marxism believes that "ideal is rooted in reality, the necessity of practice, the realization of the ideal must rely on the correct historical practice activities [3]". The youth is strong, the country is strong, whether the youth can be established the correct belief coordinates, it is not only the growth of the individual but also the future of the country and nation. To integrate the spirit of Beidahuang into the cultivation of mass entrepreneurship and innovation type talents is not only the inheritance of the red gene of the Chinese, but also the inevitable requirement of the self-worth realization of the young people in the new era. In the history of the Beidahuang, a generation of pioneers had emerged to share the country's worries, such as the returned soldiers Ren Zengxue of the conquer quagmire, the pioneering teacher Huang Zhenrong of frozen nine toes, and so on. The young people who are determined to devote precious years of youth, knowledge and wisdom to the development of the motherland, their own growth process will produce rich social value and lay the seeds for the Beidahuang in the hard-working pioneering years. These historical marks provide historical basis and facts for reference in the training of mass entrepreneurship and innovation talents, which have an important spiritual support for the establishment of young people's lofty aspirations, and the study and practice of the Beidahuang spirit is the effective channel and focus of inheriting the pioneering spirit of hard struggle, so that the young people in the new era can devote themselves more consciously to the construction of modern agriculture, and devote themselves to the social practice of realizing the great rejuvenation of the Chinese nation with their own actions, so as to truly "have faith in their heart, direction in the future and power in action ".

\section{The cultivation of talents in colleges and universities needs the support of spiritual details}

The generations of the Beidahuang people devoted life and youth to create the Beidahuang spirit, however, the spirit of Beidahuang still exudes inexhaustible vitality and has strong vitality in the new period. Agricultural and forestry colleges and universities should make full use of the unique spiritual wealth of the Beidahuang to guide young people to draw spiritual strength, grasp the essence with the spirit of Beidahuang, strive to integrate, and understand deeply the basic content and connotation essence of the
Beidahuang spirit. Heilongjiang Bayi Agricultural University as its own university in Heilongjiang Farm \& Land Reclamation is not only the development builder of the Beidahuang but also the creator, practitioner and communicator of the Beidahuang spirit. Heilongjiang Bayi Agricultural University consciously shoulders the mission of inheriting the spirit of Beidahuang, and focus on the cultivation of modern agricultural talents with the spirit of Beidahuang, therefore, Heilongjiang Bayi Agricultural University is also known as "Whampoa Reclamation Area". In the process of training mass entrepreneurship and innovation type talents, it has a great impetus to the qualified constructors and successors of agricultural modernization who highly identify with the spiritial connotation of Beidahuang, have clear professional goals, outstanding comprehensive ability, and energetic spirit.

The development and construction needs Mass entrepreneurship and innovation talents

Heilongjiang Farm \& Land Reclamation in the new era is facing the transformation, stripped the function of government and enterprise, the reform of Heilongjiang Farm \& Land Reclamation is bound to be accompanied by labor pain, and needs mass entrepreneurship and innovation talents. Therefore, it is of great significance for the college students who have invested in the agricultural modernization construction of Heilongjiang Farm \& Land Reclamation in the transition period to identify with the Beidahuang spirit, however, identifying with the Beidahuang spirit can identify with the history, the historical contribution, the inevitability and epochal nature of Heilongjiang Reclamation area reform. We will be able to better play the "painstaking efforts of pioneering spirit, the innovative spirit of daring to open, the unity spirit of pay attention to the interest of the whole, the service spirit of the selfless dedication of the Beidahuang spirit.

\section{The revolutionary spirit needs to be passed on from generation to generation}

China's problems still need to be solved by the Chinese themselves, and China's construction can only rely on the Chinese themselves. The spirit of Beidahuang is a bright pearl in the great spirit of the Chinese nation, and the contemporary college students can identify with the spirit of Beidahuang through practical activities and can identify with other great spirits, especially the revolutionary spirit, such as the Yan'an spirit and the Long March spirit. The problem of belief is the biggest problem, is the most fundamental problem. When the college students believe firmly, the country becomes rich and strong and achieves the ideal state of the people have faith, the country has strength, the nation has hope. 
The combination of the Beidahuang spirit on training agricultural and forestry talents with mass entrepreneurship and innovation

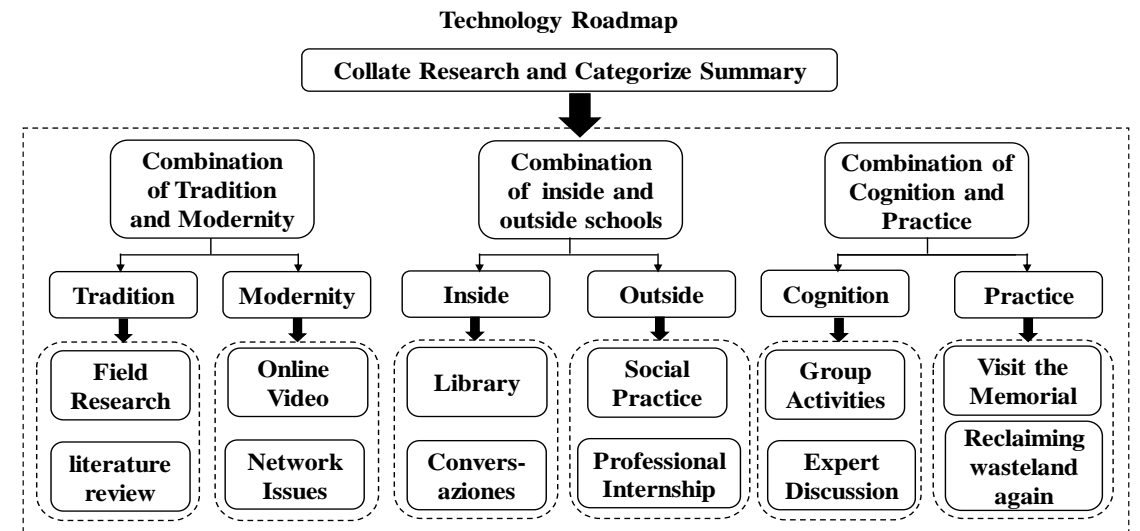

Fig-1: The three modes of practical teaching with the spirit of Beidahuang

Heilongjiang Bayi Agricultural University insists on "Three Combinations" in the process of mass entrepreneurship and innovation talents training (Fig-1), that is, the combination of tradition and modernity, inside and outside school, and cognition and practice. The combination of tradition and modernity means that we can use the traditional way to let the students understand the spirit of Beidahuang, such as field research, reading books, teacher lectures, and literature review. Modernity means that we can visit old reclamation people, and their experiences and stories made a video posted online, using the power of the media to let more people know and understand the spirit of Beidahuang. The combination of inside and outside school means that we can make use of the abundant resources in the school, such as the university history museum of the spirit of Beidahuang, library, conversazione, and so on to study the spirit of Beidahuang. Outside school means that we should make use of the winter and summer vacation to carry out extracurricular activities under the premise of understanding the spirit of Beidahuang, such as social practice, professional internship and so on. The practice is the basis of cognition, practice plays a decisive role in cognitive activities under the premise of the combination of cognition and practice. Cognition means that we can make use of university resources, such as conducting group activities and organizing expert discussions. Practice means that we can make use of social resources, such as visit the memorial, re-walking the reclamation wasteland and so on. We only really let people feel the spirit of Beidahuang and put into practice, creating the right understanding, and finally using the correct understanding to guide the practice.

\section{CONCLUSION}

Promoting the construction of an innovative country cannot be separated from the cultivation of high-level innovative talents. Colleges and universities are at the forefront of socialist ideological construction, and undertake the important task of cultivating all kinds of outstanding talents with a sense of historical mission, social responsibility, innovative spirit and practical ability. Construct a set of mass entrepreneurship and innovation teaching mode of agricultural and forestry talents with rich form, substantial content and strong feasibility, effectively promoting the high recognition and conscious inheritance of the nation among the college students in the new era, especially the college students in agriculture. It cannot only make the spiritual brilliance of the Chinese nation shine more brightly in the new era, but also make the young people turn their faith into the impetus of tenacious struggle, and provide the inexhaustible power for realizing the great rejuvenation of the Chinese nation Chinese Dream.

\section{ACKNOWLEDGEMENTS}

This work was supported by General Research Projects on Higher Education and Teaching Reform in Heilongjiang Province (SJGY20190482), Teaching Research Project of Review and evaluation of Heilongjiang Bayi Agricultural University (NDJY1801), The Doctoral Scientific Research Start-up Foundation of Heilongjiang Bayi Agricultural University of China (No. XYB2014-04), Youth Special Project in the 13th Five-Year Plan of Education Science in Heilongjiang Province (GJD1318025).

\section{REFERENCES}

1. Xi, J. P. (2017). Building a Well-off Society in an All-round Way and Winning the Great Victory of Socialism with Chinese Characteristics in the New Era -- Report at the 19th National Congress of the Communist Party of China. Xinhua Net.

2. Yan, D. D. (2014). Local Aesthetics and Cultural Perspectives in the Literature of the Beidahuang Corps. Magazine Office of Study \& Exploration, (7): 143-146.

3. Fang, X., \& Pan, M. W. (2017). The Realistic View and Ideal View in the Perspective of Marx's Practical Philosophy. Philosophical Trends, (4): 34-40. 